Article

\title{
Ideal Operation of a Photovoltaic Power Plant Equipped with an Energy Storage System on Electricity Market
}

\author{
Markku Järvelä * and Seppo Valkealahti \\ Laboratory of Electrical Energy Engineering, Tampere University of Technology, P.O. Box 692, \\ FI 33101 Tampere, Finland; seppo.valkealahti@tut.fi \\ * Correspondence: markku.jarvela@tut.fi; Tel.: +358-50-366-6194 \\ Academic Editor: Eric Ka-wai Cheng \\ Received: 22 June 2017; Accepted: 19 July 2017; Published: 23 July 2017
}

\begin{abstract}
There is no natural inertia in a photovoltaic (PV) generator and changes in irradiation can be seen immediately at the output power. Moving cloud shadows are the dominant reason for fast PV power fluctuations taking place typically within a minute between 20 to $100 \%$ of the clear sky value roughly 100 times a day, on average. Therefore, operating a utility scale grid connected PV power plant is challenging. Currently, in many regions, renewable energy sources such as solar and wind receive feed-in tariffs that ensure a certain price for the energy. On the other hand, electricity markets operate on a supply-demand principle and a typical imbalance settlement period is one hour. This paper presents the energy, power and corresponding requirements for an energy storage system in a solar PV power plant to feed the power to the grid meeting the electricity spot markets practices. An ideal PV energy production forecast is assumed to be available to define reference powers of the system for the studied imbalance settlement periods. The analysis is done for three different PV system sizes using the existing irradiance measurements of the Tampere University of Technology solar PV power station research plant.
\end{abstract}

Keywords: solar PV; energy storage systems; electricity markets

\section{Introduction}

Penetration of solar PV power production is increasing rapidly. In recent years, the annual growth rate has been approximately $40 \%$. At the end of 2016, global installed production capacity was over 300 GW-an increase of over $70 \mathrm{GW}$ of new solar PV compared to 2015 [1]. Subsidizes have made it possible for solar PV to be a profitable investment and this has been the driving force behind the rapid increase in the past years. Europe was the first region to implement subsidizes on a large scale. Lately, renewable energy sources such as solar and wind power are widely subsidized all around the world. Typical forms of subsidies are feed-in tariffs that guarantee a certain price for the energy fed to the electric grid. As prices of solar PV systems have come down, subsidies have also decreased. Soon they will no longer be offered or needed, and renewable energy sources will compete directly with traditional power generation and meet all the market necessities.

PV generator output power depends mainly on the irradiance to the cells and partly on their temperature. There is no natural inertia in a PV generator, so irradiance changes could step down (or up) the power from 100 to $20 \%$ of the nominal power in tens of seconds several times in a day, on average [2]. Fast irradiance changes are primarily caused by moving clouds, and various models have been developed to predict PV generator output power and other quantities as a function of irradiance and PV generator land area. Geographical distribution of solar PV plants smooth out the 
power fluctuations to some extent but some form of compensation is still needed to mitigate the possible grid instability problems [3].

The electricity market works on the supply-demand principle, i.e., bids and offers form the price. Buyers are required to consume and sellers to generate the purchased and sold energy, respectively, during the imbalance settlement period (ISP). Typically, this period is one hour but, for example, in the European Parliament, it has been proposed that the imbalance settlement period should be changed to $15 \mathrm{~min}$ in all European Union (EU) control areas [4].

A traditional electric grid consists of base power plants and load following power plants. When power plants that rely on intermittent energy sources, such as solar and wind, are connected to the grid, more and more peaking power plants are needed, since load and generation must always be in equilibrium. Load following power plants ensure the balance between load and generation by reacting to frequency changes in the grid within minutes. Traditional base power plants, e.g., nuclear and coal, typically operate in constant power mode, and they have no strict rules on how to feed energy to the grid. However, this will not be the case when the share of renewables increases in the energy mix. Some transmission system operators have already given requirements regarding ramp-rate limits $[5,6]$. It can be foreseen that the system operators will give even stricter rules for the operation of electricity producers in the grid in the future transmission.

The basic function of a grid connected energy storage system (ESS) is time-shifting of load and generation. In addition to bulk energy applications, this simple feature makes it possible to use them in many ways, such as ancillary services in general, customer energy management and integrating renewable energy sources into an electric grid [7]. Feasibility of these applications can be evaluated economically. ESSs can be used as an alternative to other investments. In some cases, consumers can take advantage of electricity price fluctuations and reduce the overall costs by using energy storages for load shifting [8].

Energy storage systems can be divided into different groups based on their operation principle. Pumped hydro storages (PHS), compressed air energy storages (CAES) and flywheels can be classified as mechanical, super capacitors and magnetic energy storages as electrical and batteries and flow batteries as electrochemical energy storages. Different technologies have different characteristics, such as power and energy density, efficiency, response time, lifetime, investment and operation costs, and technical maturity. Therefore, application specific requirements must be well understood [9].

It is expected that in the future solar PV power producers will be required to implement production profile manipulation via external energy storages. Basic energy and power capacity requirements for the PV integrated ESSs are already known. For example, they have been derived from the so-called worst fluctuation model verified both with real measurement data from PV power plants and simulations [10]. The next step is to find out the requirements for the ESS when more sophisticated $\mathrm{PV}$ power production profile shaping is needed. One interesting topic is the operation of large grid connected utility scale PV power plants feeding the generated power to the grid on the electricity market. When feed-in tariffs are not available in the future, PV power production must meet the ISP requirements on the electricity market.

This paper examines the energy and power capacity requirements for an ESS in a grid connected PV power plant meeting the electricity market requirements. The analysis is done for three different PV system sizes and two different ISP lengths. Similar production profile shaping studies have been done before [11]. The novelty of this paper lies in its deeper analysis of ESS requirements. Particularly, energy capacity requirements were analyzed thoroughly. For example, by altering the observation period length it was found that highest energy capacity requirements take place very seldom and quite randomly around the year. Therefore, there is potential for savings when sizing the energy storage by recognizing the instances that cause the highest energy capacity requirements beforehand. 


\section{Measurement Data}

Measurement data consists of irradiation measurements from a solar PV power research plant located on the rooftop of the Tampere University of Technology (TUT) in Finland, in Northern Europe. Pyranometers used in the measurements are in parallel with optimally installed fixed PV modules at a $45^{\circ}$ angle from the horizontal plane facing closely due south. Sampling rate used in this study was one sample per second [12].

Analysis is based on the irradiance measurements from 2015. Due to some gaps in the measurement data, caused for example by system service, data of 16 days was missing: four spring, eight summer and four autumn days. Measurement data covers 349 days, i.e., 95.6\% of the year. Unfiltered irradiation measurement for three days shown in Figure 1 demonstrate the large differences between days. The first example is a fully cloudy day, the second one a partly sunny day with some heavy clouding and the third one a clear sky, sunny day without clouds. Fully cloudy days make 37\%, partly cloudy $55 \%$ and clear sky, sunny days $8 \%$ of all days. Some of the fully cloudy days during winter months could be explained by snow covering the pyranometer. Fully cloudy and partly cloudy days are evenly distributed along the year, but half of the clear sky, sunny days occurred on two instances, lasting six and seven consecutive days, in spring and summer, respectively.
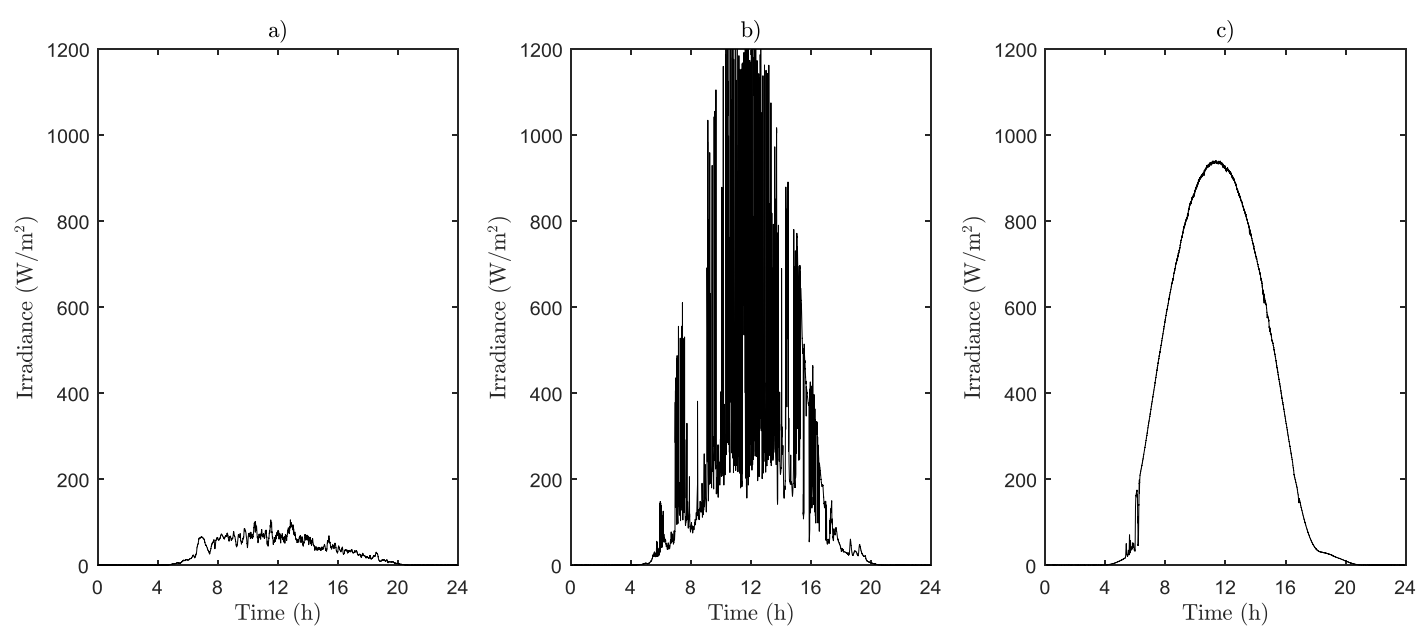

Figure 1. Irradiation measurements of one sensor on (a) 26th of April; (b) 23rd of April and (c) 12th of August in 2015.

\section{Method of Analysis}

\subsection{PV Generator Model}

The studied PV generator sizes are 0.1, 1 and $10 \mathrm{MW}$ and their direct land areas are 2500, 27,000 and $300,000 \mathrm{~m}^{2}$, respectively. These power ratings and land areas represent a typical commercial rooftop power plant and small and medium sized utility scale power plants [13]. Direct land area includes solar panels, walkways between panel rows, roads and building structures. Therefore, the bigger the PV power plant power is, the larger is the required relative area. In addition, it is not always necessary to have such a compact panel layout on ground-mounted systems as on rooftops where the installation area is limited.

PV generator output power is directly proportional to the irradiance. Geographical distribution of PV panels smoothens the PV generator output power because irradiance changes do not occur simultaneously on all panels. PV generator output can be modelled by low-pass filter method [14]. 
Inputs of the model are direct land area of the PV generator and irradiance measurement from a single point. Effective irradiance $G_{S}$ of the PV generator can be expressed as

$$
G_{s}(t)=\frac{G(t)}{\tau s+1}
$$

where $G$ is the irradiance on a single point, $t$ is time and $s$ is the Laplace transfer function. The low-pass filter time constant $\tau$ is calculated as follows

$$
\tau=\frac{\sqrt{A}}{2 \pi \cdot a}
$$

where $A$ is the direct land area of the PV generator and $a$ is an experimental coefficient. The value of the coefficient $a=200 \mathrm{~Hz} \times \mathrm{m}$ is obtained from a fit to the cutoff frequencies of the power spectra of various PV power plants plotted as a function of the plant area [14,15]. Temperature dependency of the PV generator is ignored, because irradiance transitions are much faster than temperature changes of the modules due to their thermal mass.

Filtered standard test condition (STC) irradiance of $1000 \mathrm{~W} / \mathrm{m}^{2}$ is scaled to correspond to the nominal PV power plant power $P_{\text {nom }}$. Operation of spatial smoothing algorithm is demonstrated in Figure 2 by comparing unfiltered irradiance measurement to effective irradiances of $0.1,1$ and $10 \mathrm{MW}$ PV generators. The bigger the PV generator direct land area is, the slower it reacts to changes in irradiation. Fast irradiance fluctuations lasting only for some seconds, e.g., at 12:01, does not cause big changes in effective irradiance of $10 \mathrm{MW}$ PV generator, whereas the fluctuation can be seen clearly at 0.1 MW PV generator.

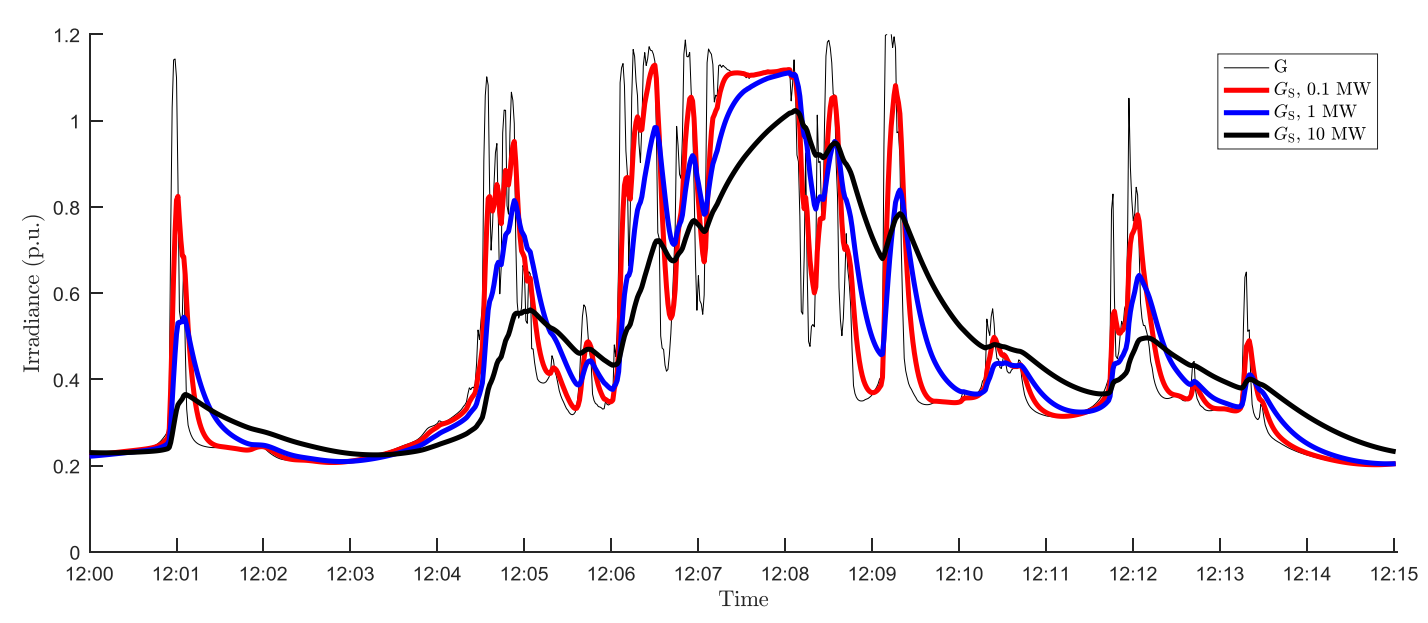

Figure 2. Unfiltered measured irradiance and effective irradiances of 0.1,1 and $10 \mathrm{MW}$ PV generators on the 23rd of April. Irradiance values have been normalized to STC irradiance.

\subsection{Electricity Production Forecasting and Spot Markets}

There are different methods for PV power production forecasting. Physical models are numerical analysis of equations that describe the physical state and dynamic motion of the atmosphere. Statistical methods, such as neural networks and time series, are based on historical patterns. Several factors affect the forecast accuracy, e.g., forecast horizon, input data, forecast model, location of the PV power production and the regional weather characteristic [16].

Using real electricity production forecasts would always lead to model specific results to some extent. Furthermore, a publicly available reliable PV power production forecast is still missing for our measurement site area. Therefore, an ideal PV power productions forecast has been applied in this study, i.e., energy yield during imbalance settlement period is calculated based on a PV generator 
model from single point irradiance measurements. Accordingly, reference grid feeding power for the PV plant is calculated from the energy yield of the ISP.

The Nordic energy market Nord Pool has day-ahead and intraday market services. Offers and bids for day-ahead market must be submitted 12:00 CET on the previous day and intraday market operates almost on real time [17]. Therefore, the PV power forecast horizon for day-ahead market is around $18-30 \mathrm{~h}$ and for the intraday market only a few hours. The basic ISP on the market is one hour and it is shown to be $15 \mathrm{~min}$ in the future. Therefore, these two ISP times have been used in this study.

\subsection{Energy Storage Model}

Inverter, transformer and other PV system losses are well known to depend on the received irradiance and system component temperatures. However, these losses depend on the applied technology and are not considered in this study in order to obtain results of general relevance. Further, the PV system is assumed to operate always at the maximum power point (MPP). Also, the energy storage system was assumed to be ideal, i.e., no losses were considered during charging, discharging etc. of the ESS, to obtain generally applicable results.

It is a common industry standard in utility scale PV systems to dimension the PV generator nominal peak power to be higher than the nominal power of the inverter and transformer. Typical over dimensioning factors are 1.2-1.4 times the nominal power of the inverter. This practice has many benefits, e.g., smoother power output, better energy yield during winter, easier forecasting of power, etc. As PV panels become cheaper compared to the overall balance of system costs, over dimensioning will be more common in the future. However, for the sake of simplicity, it is assumed that inverter and PV generator nominal powers are the same.

Cloud enhancement is a phenomenon where measured irradiance can temporarily exceed the clear sky irradiance value and it can be observed on days with intermittent clouds [18]. The effect of cloud enhancement can be seen clearly in Figures $1 \mathrm{~b}$ and 2. In 2015, the highest measured irradiance peak was $1379 \mathrm{~W} / \mathrm{m}^{2}$. There were altogether $50 \mathrm{~min}$ of instances during 40 days where irradiation was over $1200 \mathrm{~W} / \mathrm{m}^{2}$. The spatial smoothing filter reduces the time to 28,13 and $2 \mathrm{~min}$ and occurrence days to 29, 14 and 3 in $0.1,1$ and 10 MW PV generators, respectively. Due to their very short duration, power spikes caused by cloud enhancement have a negligible effect on the energy capacity requirement for the ESS. The spikes might have a relevant theoretical effect on the power capacity requirements, if the inverter does not curtail the output power. Because PV generator and inverter nominal power are the same, power spikes caused by cloud enhancement are curtailed. In addition to this, the system is set to be in standby mode when energy yield during imbalance settlement period is less than $1 \%$ of the nominal value, i.e., late in the evening and early on the morning. Due to these reasons, the total energy yield was $99.05-99.10 \%$ of the optimal value for the studied PV generator sizes and applied imbalance settlement periods. The applied model was more realistic with respect to real PV power production by ignoring the spikes and periods of low irradiance.

The applied control algorithm for the energy storage system is simple. Power fed to the grid is constant and the energy fed to the grid is equal to the PV generator production for each imbalance settlement period, because an ideal PV power production forecast is used. Operation of the system can be expressed as

$$
\begin{gathered}
P_{\text {ref }}=\frac{E_{\mathrm{PV}}}{t_{\mathrm{ISP}}} \text { and } \\
P_{\text {grid }}=P_{\text {ref }}=P_{\mathrm{PV}}-P_{\text {bat }},
\end{gathered}
$$

where $P_{\text {ref }}$ is reference power, $E_{\mathrm{PV}}$ is PV generator energy yield during ISP, $t_{\mathrm{ISP}}$ is ISP length, $P_{\text {grid }}$ is power fed to grid, $P_{\mathrm{PV}}$ is $\mathrm{PV}$ generator output power and $P_{\text {bat }}$ is battery power so that positive value corresponds to discharging and negative value to charging. This means that the energy storage state of charge $(\mathrm{SoC})$ is varying only during the imbalance settlement periods and returns to the base value at the end of each period. This behavior can be seen in Figure 3, where the energy capacity of ESS, i.e., state of charge, returns to the reference value of $0 \mathrm{~h}$ at the end of each settlement period of $1 \mathrm{~h}$. 
Accordingly, the total energy generated by the PV plant during each settlement period equals with the energy fed to the grid.
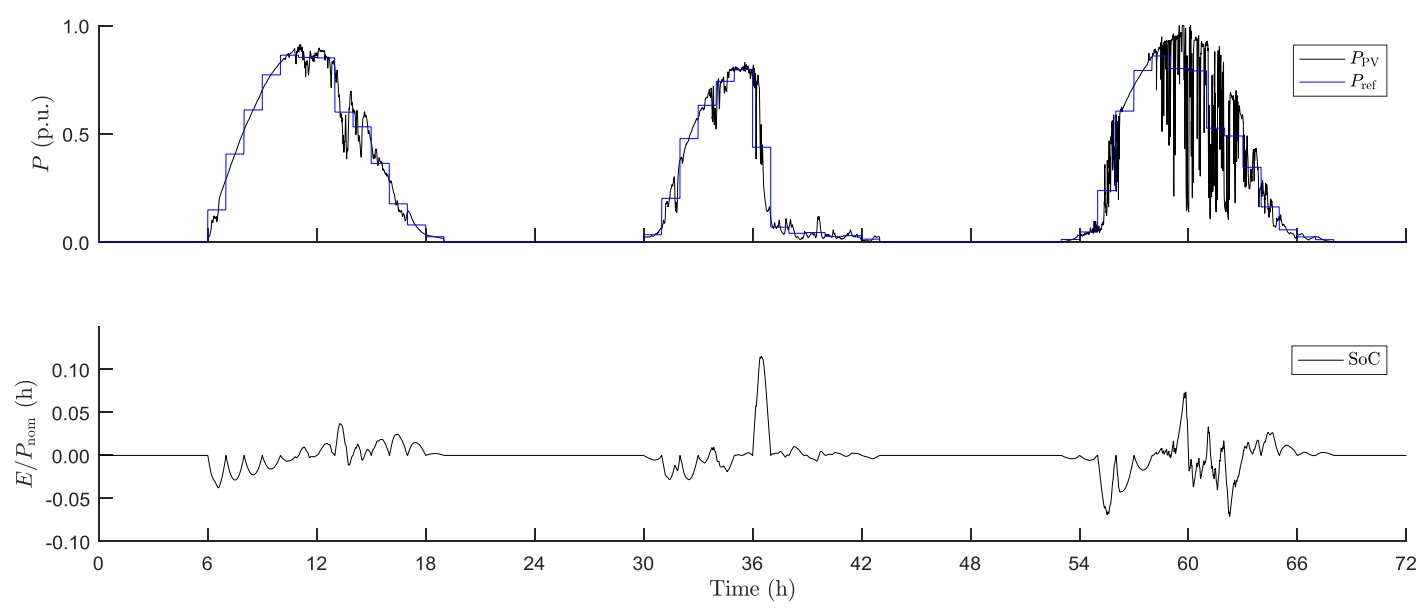

Figure 3. On top is the PV generator output power and the power fed to the grid, i.e., reference power for SoC for one hour ISP, and below is the state of charge of ESS during three days from 11 April to 13 April in 2015.

\section{Results}

\subsection{Energy Storage System Requirements}

ESS energy and power capacity requirements are presented in Table 1. Energy capacity requirement $E_{\mathrm{ESS}}$ is the difference between the maximum and minimum state of charge during one year with respect to the PV plant nominal power. It describes how many hours the ESS needs to be able to deliver the nominal power. Accordingly, power capacity requirement $P_{\text {ESS }}$ is the maximum absolute power ESS needs to be able to deliver or receive with respect to the PV plant nominal power.

Table 1. ESS energy and power capacity requirements with respect to the PV plant nominal power for compensating the output powers of the studied PV generators for 15 and $60 \mathrm{~min}$ ISP on the electricity markets.

\begin{tabular}{|c|c|c|c|c|}
\hline \multirow{2}{*}{$\begin{array}{c}\text { PV Generator Size } \\
\text { (MW) }\end{array}$} & \multicolumn{2}{|c|}{$\mathbf{E}_{\text {ESS }} / \mathbf{P}_{\text {nom }}(\mathrm{h})$} & \multicolumn{2}{|c|}{$\mathbf{P}_{\text {ESS }} / \mathbf{P}_{\text {nom }}$ (p.u.) } \\
\hline & $60 \mathrm{~min}$ ISP & $15 \mathrm{~min}$ ISP & $60 \mathrm{~min}$ ISP & $15 \mathrm{~min}$ ISP \\
\hline 0.1 & 0.36 & 0.093 & 0.85 & 0.83 \\
\hline 1 & 0.36 & 0.093 & 0.78 & 0.78 \\
\hline 10 & 0.36 & 0.091 & 0.78 & 0.75 \\
\hline
\end{tabular}

As is shown in Table 1, the energy capacity requirement for ESS is directly proportional to the PV plant size since the values are normalized to the PV plant nominal power. For 60 min ISP, the ESS needs to be able to deliver the PV plant nominal power for $0.36 \mathrm{~h}$. This result is in line with earlier studies on the ESS energy capacity requirements to compensate PV power plant fluctuations with respect to different ramp rate limits. For example, the ESS energy capacity requirement for a $3 \% / \mathrm{min}$ ramp rate limit of the PV plant nominal power was around $0.3 \mathrm{~h}$ decreasing with increasing ramp rate limit [15]. This is plausible since the grid feeding power varies very smoothly when a $3 \% / \mathrm{min}$ ramp rate limit is applied, which is close to the approach of this study with a constant grid feeding power during each ISP.

The ESS energy capacity requirement decreases almost linearly with decreasing length of the ISP time being just over $0.09 \mathrm{~h}$ when $15 \mathrm{~min}$ ISP is applied. This linear decrease of the required ESS energy 
capacity with decreasing ISP time is caused primarily by the used method of analyses, i.e., use of an ideal production forecast and a constant grid feeding power for each ISP. The probability of having very different irradiation behavior within an ISP decreases with decreasing ISP time leading directly to decreasing capacity requirements. However, this apparently trivial result provides an important hint for the future. The ESS energy capacity requirement can be decreased considerably with decreasing ISP time and by improving the PV power production forecasting accuracy.

Power capacity requirement for ESS is also directly proportional to the PV plant size being roughly $80 \%$ of the PV plant nominal power (Table 1). It decreases only slightly with increasing PV plant size due to increased smoothing of power fluctuations with increasing PV plant area. Power capacity requirements for ESS are nicely in line with irradiance fluctuations caused by cloud shading [2]. On rare occasions, shading strength of a moving cloud can be as high as $90 \%$ and, accordingly, duration of a shading transition can be of the order of one second. Thus, it is very rare that an irradiance transition will have both features at the same time leading to power capacity requirements close to the PV plant nominal power. Power capacity requirements are almost the same for both ISP times, since single fast power fluctuations having high shading strength define the maximum capacity requirements. Therefore, the length of the ISP does not affect to the power capacity requirements. Small differences in Table 1 are only of statistical origin.

The energy capacity requirement for ESS decreased with decreasing length of the ISP time when using the full one year observation period of 2015, but the power capacity requirement did not. The effect of the observation period length on the energy capacity requirement was studied more closely to particularize these findings. The required energy capacities are shown in Figure 4, when the observation period is one day and one month before the observation point. The highest energy capacity requirements for 15 and $60 \mathrm{~min}$ ISP times and observation period of one month are quite close to the values based on the data of one year shown in Table 1, which confirms that measurement data for this time period provides reliable overall results. However, variations along the year are considerable and the seasonal changes are clearly visible, i.e., energy capacity requirement during winter is less than during summer, as expected. The overall energy capacity requirement also decreases slightly with shortening observation period and only few occasions cause high requirements while using one day observation period. This implies that much lower ESS energy capacities can be used in practice than indicated in Table 1 to meet the electricity market requirements for most of the year. If some occasional power delivery failures to the electricity market are allowed or could be foreseen beforehand to make corrective market action, considerable savings in sizing ESS can be achieved.
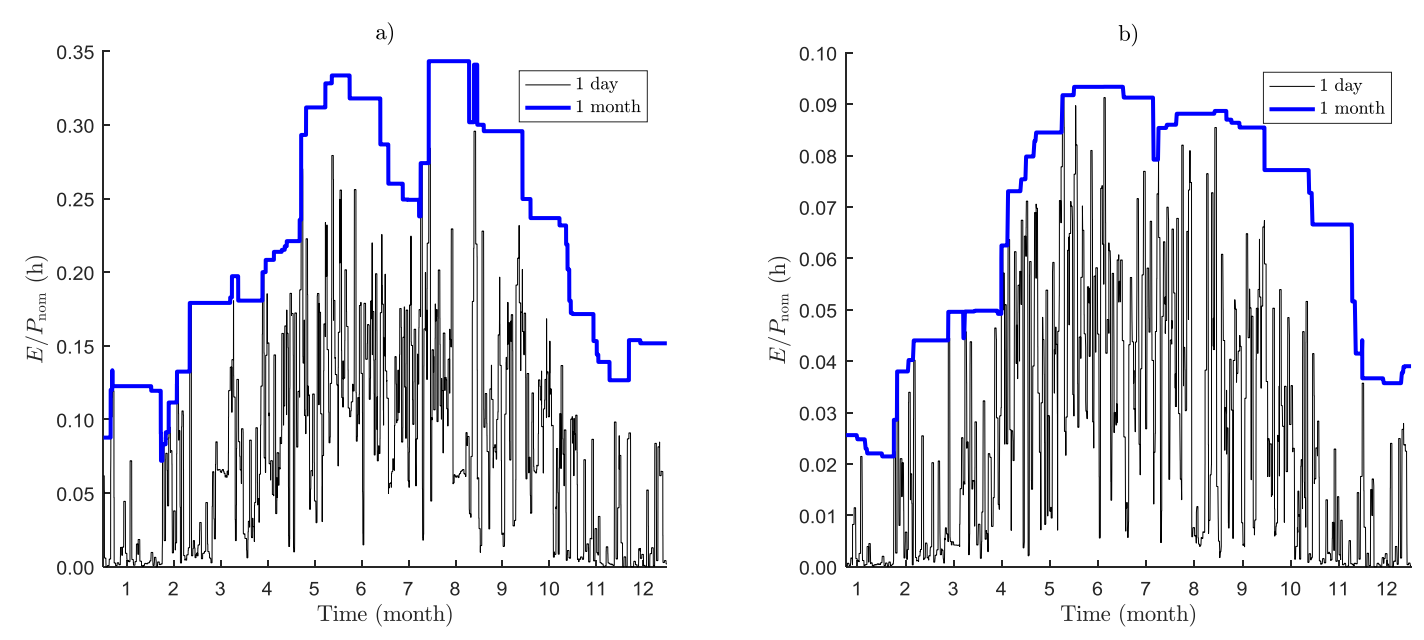

Figure 4. Required ESS energy capacities for (a) $60 \mathrm{~min}$ and (b) $15 \mathrm{~min}$ ISP times shown at the end of the observation periods of 1 day and 1 month for the $0.1 \mathrm{MW}$ PV plant in 2015. 
The probability density distributions of the ESS energy capacity requirements for the studied ISP times using observation periods of the ISP time (15 $\mathrm{min}$ or $60 \mathrm{~min}$ ), one day and one month are shown in Figure 5. The distributions for both ISP times are qualitatively similar, only the energy scales are different. Most of the time, the ESS energy capacity requirement is lower than the required highest energy capacity and, in practice, only half of the required maximum capacity is enough for over $99.5 \%$ of time of the year. Therefore, the required energy storage capacity could be smaller if the peak periods, i.e., periods of plentiful power fluctuations, could be recognized beforehand. Then, a tiny portion of the energy yield could be sacrificed to meet the electricity marked terms with a smaller ESS.

The distributions of one day and one month observation periods in Figure 5 show how the occasions requiring high ESS energy capacity are distributed among days and months of the year. Roughly half of the days and months cause the high requirements taking place around the summertime (Figure 4). The occasions that cause high ESS energy capacity requirements take place very seldom and quite randomly around the year. Fluctuations taking place in the wintertime cause most of the low requirements as expected. Because the maximum energy capacity requirements are set by power fluctuations occurring during the summer season, results are also applicable to similar climatic conditions, i.e., most of Europe [15].
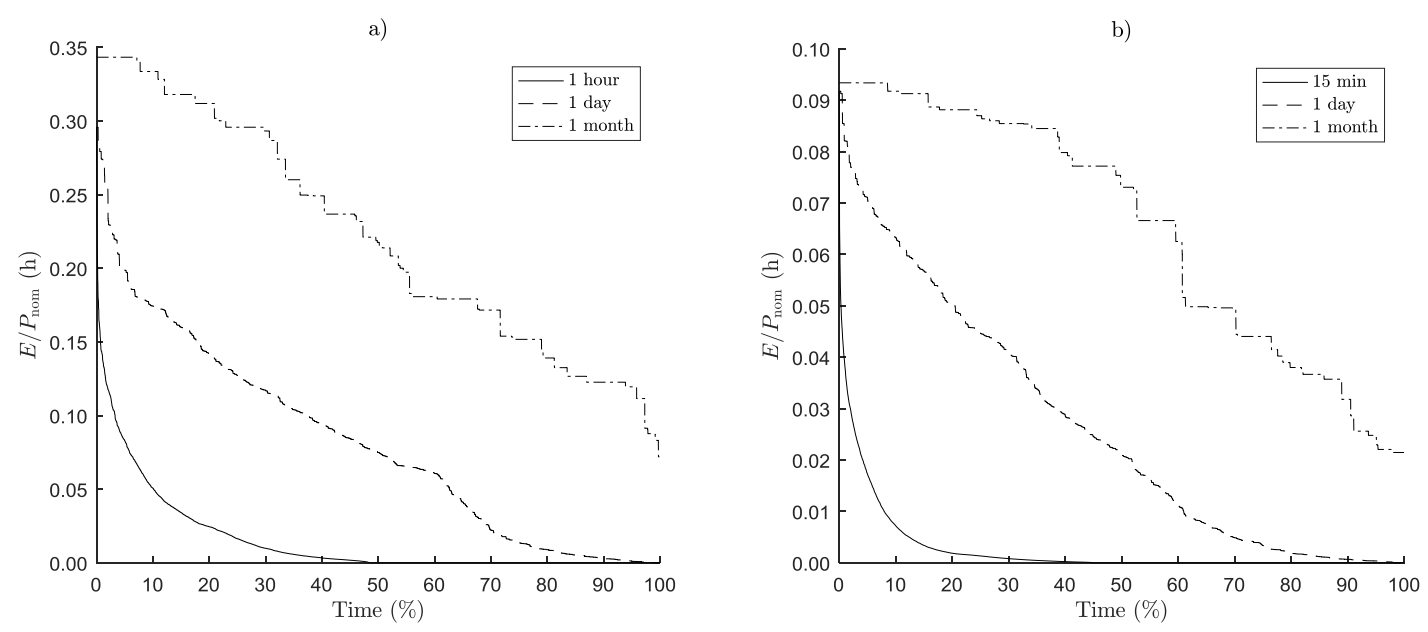

Figure 5. Probability density distributions of the ESS energy capacity requirements using observation periods of the ISP time, one day and on month in 2015 for (a) $60 \mathrm{~min}$ and (b) $15 \mathrm{~min}$ ISP times.

Probability density distributions of ESS power capacity requirements for the studied PV generators and ISP times are show in Figure 6a. Distributions seem to be almost equal for the different PV generator sizes, only a clear difference in magnitude exists between the 15 and $60 \mathrm{~min}$ ISP times, which is in line with previous observations. As was demonstrated already in Figure 5 for the ESS energy capacity requirement, only few occasions cause high ESS power capacity requirements, but they are distributed around the year. Therefore, the results regarding power capacity requirements are applicable to PV systems located in corresponding climatic conditions, i.e., most of Europe [15].

The probability density distributions of the ESS power capacity requirement, PV generator output power and the grid feeding power of the 10 MW PV generator are shown in Figure $6 \mathrm{~b}$ for $60 \mathrm{~min}$ ISP time and observation period. On average, the ESS power is from 10 to $20 \%$ of the generator power implying that a corresponding portion of the grid feeding power goes through the ESS. This means that power goes through the ESS mostly during high irradiance periods in the middle of the day in the summertime.

ESS is constantly shaping the grid feeding power but only at a fraction of the inverter nominal power. Therefore, ESS should perform well on partial power. One feasible solution could be a hybrid energy storage system (HESS) consisting of a super capacitor and a battery. Super capacitors have 
much better cycling performance compared to batteries so they can be used to smooth out the small ripple in PV generator output power, whereas batteries can be used to compensate for bigger power fluctuations [9]. Operation of such ESSs has been studied in numerous papers [19].
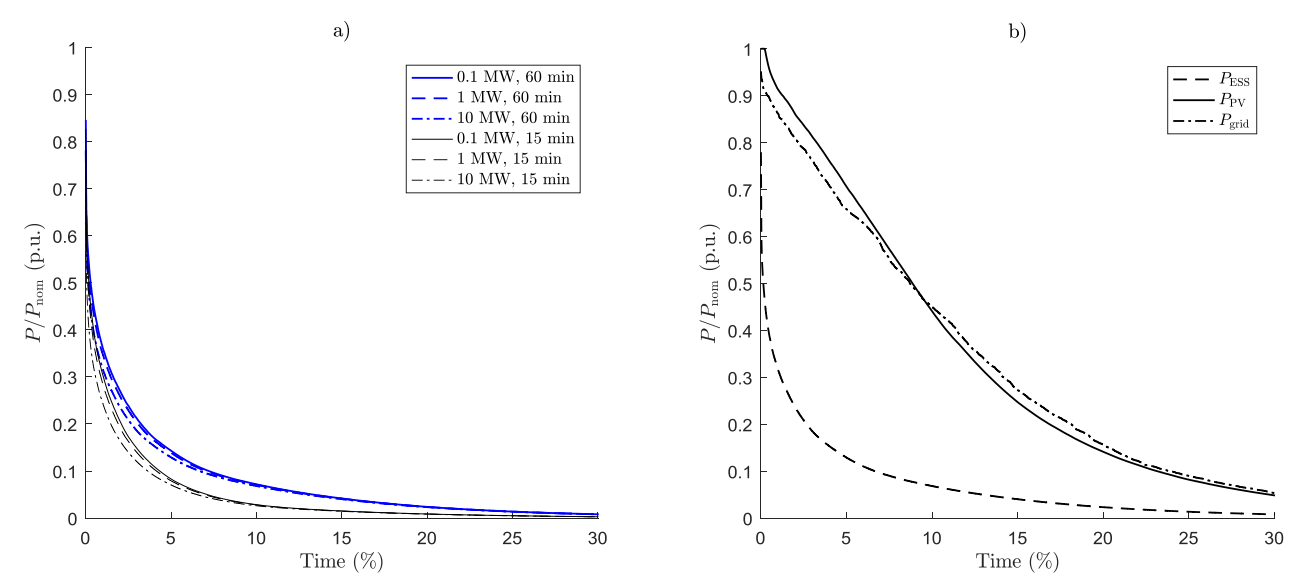

Figure 6. (a) Probability density distributions of ESS power requirements for the studied PV generators and ISP times; (b) ESS power requirement, PV generator power and grid feeding power probability density distributions for the 10 MW PV generator using $60 \mathrm{~min}$ ISP time and observation period.

\subsection{Energy Cycling Analysis}

Cycled energy is the energy charged to ESS from the PV generator and then discharged from ESS to the grid. If PV generator output power and the PV system reference power match exactly, energy cycling does not happen. The worst-case scenario is when the PV generator output power and the PV system grid feeding reference power during some period do not match at all. Then all the energy fed to the grid pass through the ESS.

The amount of cycled energy through ESS $E_{\mathrm{cyc}}$ with respect to the annual production of the PV plant $E_{\text {tot }}$ is presented in Table 2 . The amount of cycled energy is around $11 \%$ of the total energy productions for the $60 \mathrm{~min}$ ISP, which is $60-75 \%$ more compared to the $15 \mathrm{~min}$ ISP. The cycled energy is directly proportional to the PV generator nominal power decreasing only slightly with increasing system size due to increased spatial smoothing of irradiance fluctuations.

Table 2. Cycled energy through ESS in 2015 for the studied PV generators and ISP times.

\begin{tabular}{ccc}
\hline \multirow{2}{*}{ PV Generator Size (MW) } & \multicolumn{2}{c}{$E_{\text {cyc }} / E_{\text {tot }}$ (p.u.) } \\
\cline { 2 - 3 } & $\mathbf{6 0} \mathbf{~}$ in ISP & $\mathbf{1 5} \mathbf{~ m i n ~ I S P ~}$ \\
\hline 0.1 & 0.12 & 0.071 \\
1 & 0.11 & 0.068 \\
10 & 0.11 & 0.060 \\
\hline
\end{tabular}

Daily energy cycled through ESS in 2015 for the 0.1 MW PV power plant with 60 min ISP time is shown in Figure 7a as an example. The amount of cycled energy follows closely the seasonal variation of irradiation and peak PV generator power available in early summertime. All the studied PV generators and ISP times have quite similar use of ESS capacity and most of the energy cycling through ESS takes place just within a few summertime months, i.e., roughly within $10 \%$ of the time of the year (see Figure $7 b$ ). However, a considerable portion of the produced energy pass through the ESS all through the year (see Figure 7c). 

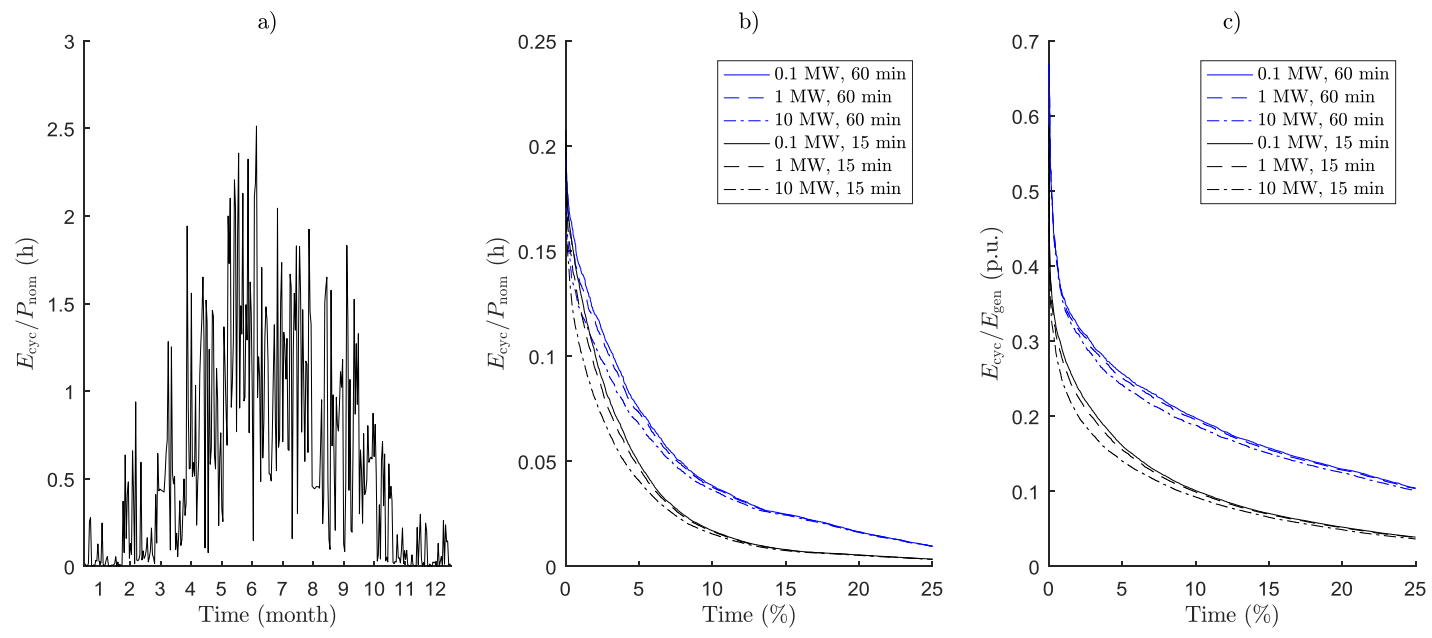

Figure 7. (a) Daily energy cycled through ESS in 2015 for the 0.1 MW PV power plant with 60 min ISP. Probability density distributions of the cycled energy; (b) with respect to the PV generator nominal power and (c) with respect to the PV generator electricity production for the studied generators and ISP times.

From a cycled energy point of view, most cycling occurs when small and thick clouds are constantly passing over the PV generator. The amount of cycled energy through ESS in 2015 was highest on 17th of June and on the 4th of June, when using 60 and $15 \mathrm{~min}$ ISP, respectively. As can be seen in Figures 8 and 9, a huge number of power fluctuations has taken place on those days between 20 and $100 \%$ of the nominal power. These fluctuations cause a lot of ESS charging and discharging throughout the days as well as fluctuations in the state of charge of ESS. One should also note that the used ESS power capacities are almost equal for the two days and ISP times, but the used energy capacity is much smaller in case of $15 \mathrm{~min}$ ISP than in the case of $60 \mathrm{~min}$ ISP.
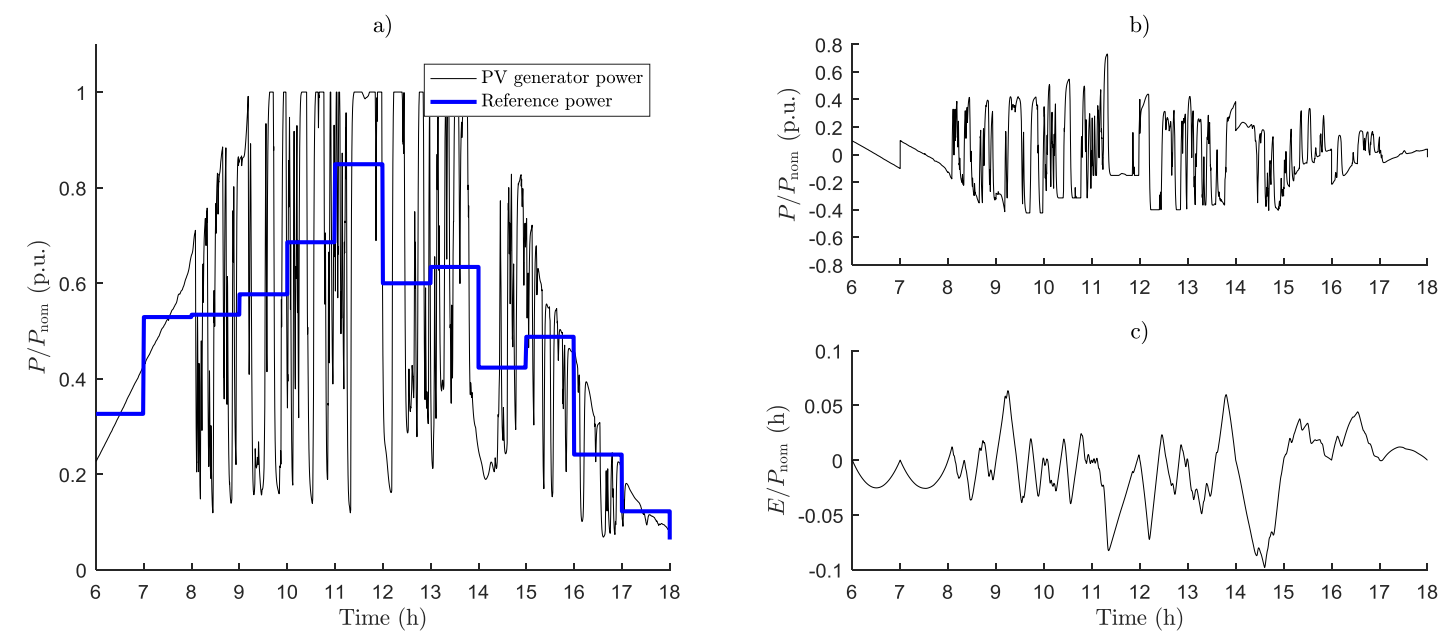

Figure 8. (a) $10 \mathrm{MW}$ PV generator power and the grid feeding reference power; (b) the corresponding power taken from the ESS and (c) the energy stored in ESS (state of charge) with 60 min ISP on 17th of June 2015. 
a)

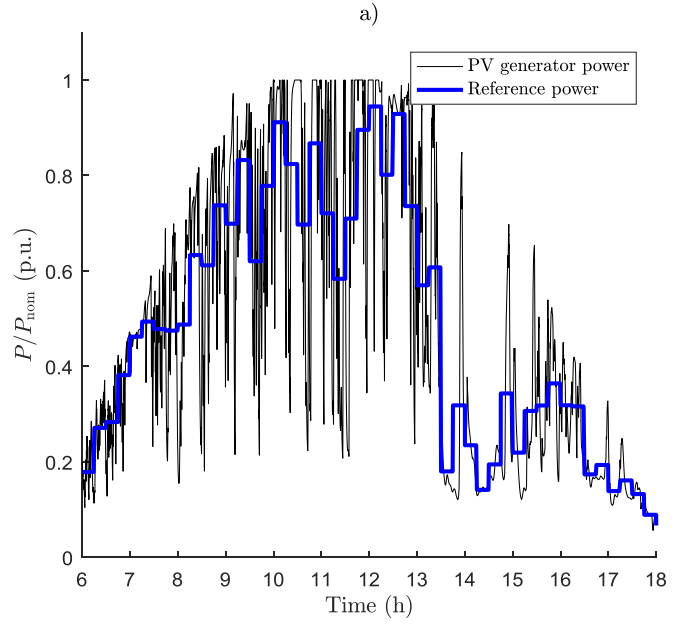

b)

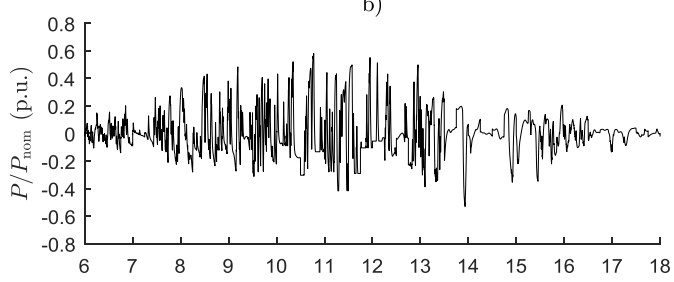

c)

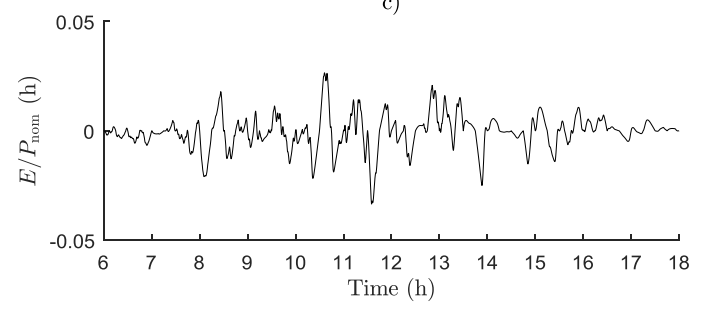

Figure 9. (a) $10 \mathrm{MW}$ PV generator power and the grid feeding reference power; (b) the corresponding power taken from the ESS and (c) the energy stored in ESS (state of charge) with 15 min ISP on 5th of June 2015.

\section{Conclusions}

PV power plants need to be equipped with energy storages, if output power smoothing or other production profile shaping is required. The electricity market is one case where at least big utility scale PV plants need to meet the spot market practices in one way or the other in the future. The use of an energy storage system is one potential solution to manipulate the grid feeding power. In this study, the ESS energy and power capacity requirements have been studied for 0.1,1 and 10 MW PV plants for meeting the imbalance settlement periods of 15 and $60 \mathrm{~min}$. Analysis is based on the TUT solar power research plant irradiance measurements in 2015 using $1 \mathrm{~Hz}$ sampling frequency to calculate spatially smoothed output powers of PV generators. For the sake of clarity, a simple ideal PV power production forecast is used as a reference for the operation of ESS and losses of the PV power plant or ESS were ignored.

The energy capacity requirement for ESS was found to be directly proportional to the PV plant size so that for a typical $60 \mathrm{~min}$ imbalance settlement period on the electricity market the ESS needs to be able to deliver the PV plant nominal power for $0.36 \mathrm{~h}$. This result is in line with earlier studies on the ESS energy capacity requirements to compensate PV power plant fluctuations with respect to different ramp rate limits. For example, the ESS energy capacity requirement for a $3 \% / \mathrm{min}$ ramp rate limit of the $\mathrm{PV}$ plant nominal power has been reported to be around $0.3 \mathrm{~h}$, decreasing with increasing ramp rate limit. The power capacity requirement for ESS is also directly proportional to the PV plant size being roughly $80 \%$ of the PV plant nominal power in line with other studies on irradiance fluctuations caused by cloud shading. ESS is operating most of the time only at a fraction of the nominal power. This must be considered when choosing the energy storage technology. Both requirements decrease only slightly with increasing PV plant size due to increased spatial smoothing of power fluctuations with increasing PV plant area. When ISP time is decreasing, energy capacity requirement is also decreasing. However, decreasing the ISP time does not considerably affect the power capacity requirement.

The probability density distributions of the ESS energy and power capacity requirements for the studied PV generator sizes revealed the highest requirements were caused by periods of high and fast irradiance fluctuations taking place during a small portion of time of the year. The high requirements are caused by periods (days) of plentiful irradiance and power fluctuations, which might be possible to predict beforehand. This is an important result when designing an ESS controller. The required energy storage capacity could be downscaled considerably, for example, by sacrificing some produced energy during those periods to meet the market terms or by paying the cost of imbalance during corresponding settlement periods. 
Daily energy cycled through the ESS was around $11 \%$ of the annual energy production of the studied PV generators, i.e., directly proportional to the generator size. The amount of cycled energy closely follows the seasonal variation of irradiation and available PV power, having peak values in early summertime. However, a considerable portion of the produced energy passes through the ESS throughout the year.

Despite using ideal forecast of the PV power production and ideal operation of the PV system in the simulations, the results were observed to be quite realistic. These results serve as a basis for more advanced studies, which should consider power losses, accuracy of real PV production forecasts, executable ESS control algorithms etc.

Acknowledgments: The research is part of the project Finnish Solar Revolution covering also the costs to publish in open access. The project is funded by Tekes, the Finnish funding agency for innovation, and 15 companies.

Author Contributions: Markku Järvelä performed the simulations. Markku Järvelä and Seppo Valkealahti both participated in analysis of the results and writing of the paper.

Conflicts of Interest: The authors declare no conflict of interest.

\section{References}

1. Jäger-Waldau, A. PV Status Report 2016, Joint Research Centre; Publication Office of the European Union: Brussels, Belgium, 2016.

2. Lappalainen, K.; Valkealahti, S. Output power variation of different PV array configurations during irradiance transitions caused by moving clouds. Appl. Energy 2017, 190, 902-910. [CrossRef]

3. Marcos, J.; Marroyo, L.; Lorenzo, E.; García, M. Smoothing of PV power fluctuations by geographical dispersion. Prog. Photovol. Res. Appl. 2012, 20, 226-237. [CrossRef]

4. European Commission. Proposal for a Regulation of the European Parliament and of the Council on the Internal Market for Electricity. Available online: http://eur-lex.europa.eu/legal-content/EN/TXT/?uri= COM:2016:861:FIN (assessed on 16 June 2017).

5. Gevorgian, V.; Booth, S. Review of PREPA Technical Requirements for Interconnecting Wind and Solar Generation; NREL/TP-5D00-57089; National Renewable Energy Laboratory (NREL): Golden, CO, USA, 2013.

6. Technical regulation 3.2.5 for wind power plants above $11 \mathrm{~kW}$. Energinet.DK: Erritsø, Denmark, 2016.

7. Palizban, O.; Kauhaniemi, K. Energy storage systems in modern grids-Matrix of technologies and applications. J. Energy Storage 2016, 6, 248-259. [CrossRef]

8. Graditi, G.; Ippolito, M.G.; Telaretti, E.; Zizzo, G. Technical and economical assessment of distributed electrochemical storages for load shifting applications: An Italian case study. Renew. Sustain. Energy Rev. 2016, 57, 515-523. [CrossRef]

9. Amirante, R.; Cassone, E.; Distaso, E.; Tamburrano, P. Overview on recent developments in energy storage: Mechanical, electrochemical and hydrogen technologies. Energy Convers. Manag. 2017, 132, 372-387. [CrossRef]

10. Marcos, J.; Storkël, O.; Marroyo, L.; Garcia, M.; Lorenzo, E. Storage requirements for PV power ramp-rate control. Sol. Energy 2014, 99, 28-35. [CrossRef]

11. Wang, G.; Ciobotaru, M.; Agelidis, V.G. Optimal capacity design for hybrid energy storage system supporting dispatch of large-scale photovoltaic power plant. J. Energy Storage 2015, 3, 25-35. [CrossRef]

12. Lobera, D.T.; Mäki, A.; Huusari, J.; Lappalainen, K.; Suntio, T.; Valkealahti, S. Operation of TUT solar PV power station research plant under partial shading caused by snow and buildings. Int. J. Photoenergy 2013, 2013. [CrossRef]

13. Ong, S.; Campbell, C.; Denholm, P.; Margolis, R.; Heath, G. Land-Use Requirements for Solar Power Plants in the United States; NREL/TP-6A20-56290; National Renewable Energy Laboratory (NREL): Golden, CO, USA, 2013.

14. Marcos, J.; Marroyo, L.; Lorenzo, E.; Alvira, D.; Izco, E. From irradiance to output power fluctuations: The PV plant as a low pass filter. Prog. Photovolt. Res. Appl. 2011, 19, 505-510. [CrossRef]

15. Schnabel, J.; Valkealahti, S. Energy Storage Requirements for PV Power Ramp Rate Control in Northern Europe. Int. J. Photoenergy 2016, 2016. [CrossRef] 
16. Raza, M.; Nadarajah, M.; Ekanayake, C. On recent advances in PV output power forecast. Sol. Energy 2016, 136, 125-144. [CrossRef]

17. Nord Pool-The Power Market. Available online: http://www.nordpoolspot.com/How-does-it-work/ (accessed on 18 May 2017).

18. Tapakis, R.; Charalambides, A.G. Enhanced values of global irradiance due to the presence of clouds in Eastern Mediterranean. Renew. Energy 2014, 62, 459-467. [CrossRef]

19. Wang, G.; Ciobotaru, M.; Agelidis, V.G. Power Smoothing of Large Solar PV Plant Using Hybrid Energy Storage. IEEE Trans. Sustain. Energy 2014, 5, 834-842. [CrossRef] 